\title{
The quest for ongoing support by parents of learners with intellectual disabilities
}

\section{Maximus Monaheng Sefotho}

Department of Educational Psychology, University of Pretoria, Pretoria, South Africa msefotho@uj.ac.za (Corresponding author)

https://orcid.org/0000-0003-0704-1983

\section{Ronél Ferreira}

Department of Educational Psychology, Groenkloof Campus, University of Pretoria, Pretoria, South Africa ronel.ferreira@up.ac.za

https://orcid.org/0000-0003-2518-7839

\section{Bernard Bongani Lushozi}

Albertina Sisulu Centre, Soweto, South Africa

bernard@albertinasisulucentre.co.za

(Received: 5 March 2021; accepted: 1 September 2021)

\begin{abstract}
In this article we explore the need for ongoing support for those parents/guardians raising children with intellectual disabilities. The aims of the study on which this article builds were: (i) to explore the experiences of support offered to parents of learners with intellectual disabilities in Soweto; and (ii) to evaluate how support services affect parents' perceptions and expectations of their children's future. Thirty-five parents of learners from four schools diagnosed with an intellectual disability were purposefully selected to participate in this qualitative research, with one focus group discussion conducted at each school. Findings highlight parents' concern about their children's future when exiting the school system. Furthermore, our findings emphasise the need for ongoing support in many aspects throughout the various developmental stages of the child's life. We propose a framework for coordinated support that may serve to guide parents to support their disabled children.
\end{abstract}

Keywords: intellectual disability, diagnosis, inclusive education, support 


\section{Background}

For any parent, the diagnosis of a child with an intellectual disability (ID) marks the start of an ongoing journey of seeking support (Correia et al., 2017). During this initial phase of awareness and acceptance, parents often engage in what the literature calls shopping behaviour or continuing to seek a second opinion in the hope that a subsequent diagnosis might offer greater hope than the first (Daroch et al., 2021). This search for a second opinion often continues throughout the child's life. In terms of the support typically provided to parents of learners with an ID, most parents experience dissatisfaction regarding the level of support they receive in dealing with their children's various unique developmental stages, especially when their children reach adulthood or exit the school system (Masulani-Mwale et al., 2016). Concerns about the future of learners who have an ID are echoed by a number of researchers. For example, Catherall and Iphofen (2006), Johnson et al. (2006), as well as Todd and Jones (2005) have asserted that this is a recurring theme in the expression of parents' hopes and fears about the prospect of their death and what the future may hold for their children with an ID when they are no longer alive. The persistent uncertainty and anxiety about what might happen to their children after exiting the school system and when they grow older gives rise to the perception among parents that they face a life-time commitment to support them (Barronet al., 2006; Chou et al., 2011; Maxwell \& Barr, 2003; Sahay et al., 2013; Singh et al., 2008). As a result of the dilemma, parents typically seek as much additional support for their children as possible in their mission to pre-empt what can be an unpredictable set of circumstances.

This study investigated the support typically provided to parents of learners with an ID. Although our emphasis is on parents of such learners, we appreciate that these learners often have comorbid disabilities that have further negative impacts (Khodeir et al., 2020).

Gautamet et al. (2014) observed that these comorbidities often place them at higher risk of other health-related issues. It is therefore critical that those who provide support for these learners allow for this.

Current studies have indicated that the demand for this kind of support far outweighs the available services (Chadwick et al., 2002; McConkey, 2011). For instance, in South Africa, people with disabilities receive monthly grants provided by the South African Social Security Agency (SASSA). Chelechele (2010, p. 24) explained that the South African "Social Grants Programmes were introduced under the Department of Social Development to address the problem of poverty, more especially for the people who cannot afford to fend for themselves due to age or disability." The disability grant dates back to 1946 as Hanass-Hancock and McKenzie (2017) have reminded us. The SASSA programme does not discriminate among applicants as long as parents can prove every month that they are indeed claiming the benefit to directly support their children.

Parents who participated in this study on the quest for ongoing support for parents of learners with an ID, reported that they have been benefitting from the SASSA disability grant in support of their children. When the data was collected, this grant amounted to ZAR1,690 
(about US\$123), which is not that much when one considers the needs of a child with an ID. For instance, medical expenses, the need for extra support, transport to medical facilities, and quality education all cost more than the grant can allow for.

Adnams (2010) noted that some of the services needed include the implementation of inclusive education that addresses learning needs along with compensation for the major service gaps that prevail for young people who have an ID. We need to keep in mind that South Africa adopted a policy of inclusive education in 2001, popularly known as the White Paper 6 as Makoelle and Malindi (2015) have noted, and Engelbrecht (2006) described inclusive education as a strategy that redresses some of the ills of the legacy of apartheid. Learners with IDs face challenges in post-school contexts because of their poor school achievements (Adnams, 2010). Those who experience learning difficulties and do not pass grades are usually progressed into the next phase after two failed attempts. Once they reach the level's terminal point, the system then rejects them. However, South Africa has developed a post-school policy to accommodate these learners and others who might not have passed their grades and those who have never been to school, but want to learn (Maringe \& Osman, 2016).

Based on the outcomes of their research, Doody (2012) and Sahay et al. (2013) argued that parents, although they meet the basic needs of their intellectually disabled children, find it hard to embrace their independence because of their concerns about their children's future and the support that will (or will not) be available to them. Their transitioning into adulthood is of particular concern to these parents (Harwick et al., 2017). The age of majority in South Africa is 18 and young people with an ID are entitled to access the disability grant themselves once they reach this age, although many experience problems of self-advocacy (Capri et al., 2018). The literature is currently silent on what happens to the transfer of rights to access the grants once a disabled person turns 18. The young adult having access to this income may exacerbate the problems caused by the lack of on-going support to the parents. There is the issue, too, of the possible "financial exploitation" of children with an ID (Capri et al., 2018, p. 4). However, it must be noted that most parents in South Africa take care of their children's interests even after they turn 18. Since parents are aware that they will most probably not live long enough to support their children throughout their adulthood, it follows that they require ongoing support from counsellors, formal institutions, and informal sources of support throughout their lives as they prepare for their children's challenging future (Hassal et al., 2005).

The aims of this study were: (i) to explore the experiences of the support offered to parents of learners with an ID in Soweto; and (ii) to evaluate how support services affect parents' perceptions and expectations of their children's future. Our research site was made up of schools in Soweto, Gauteng Province, that cater to learners who have an ID. Given that the education of learners with IDs is guided by the principles of inclusive education that use special education as their implementation strategy (Van Staden, 2011), we collected data from four schools that accommodate learners with special educational needs, particularly 
those with what the American Psychiatric Association has defined as special educational needs, particularly those with an ID (American Psychiatric Association, 2013).

\section{Method}

In line with Howitt (2010) this study followed an ideographic qualitative approach situated within an interpretivist paradigm, following Rodríguez (2011). Ideography was chosen because the experiences of participants are important sources of knowledge in a specific cultural milieu (Thanh \& Thanh, 2015) and we wanted to gain insight into the perceptions, views, and experiences of our participants. Ideography focuses on data from subjects who directly experience a phenomenon (such as parents of learners with an ID) and ideographic approaches look for unique facts (Bolbakov et al., 2020). Thirty-five parents of learners with an ID were purposively selected from four schools and they participated in focus group discussions. Data was collected from these discussions and from observations and field notes. We analysed the data thematically and will return presently to a discussion of the three themes that emerged.

\section{Research design}

We implemented a multiple case study design (see Moffatt et al., 2006). Our rationale for more than one case study was to gain "more deeply grounded varied empirical evidence" (Eisenhardt \& Graebner, 2007, p. 27) from parents of learners with an ID in Soweto. This case study design, following Kitzinger (2005 and Krueger and Casey (2015) allowed us to acquire a modest amount of comparative data (see Yin, 2012) from four focus group discussions.

\section{Sample}

Four schools in Soweto, situated within three kilometres from each other, were involved in this study. All four schools cater for learners with special educational needs. Thirty-five parents of learners who had been diagnosed with ID and who attended one of the four schools at the time participated in our study. Below is an overview table of participants.

Table 1

Overview of participants

\begin{tabular}{|l|l|l|l|}
\hline $\begin{array}{l}\text { Sex of Participants' } \\
\text { children }\end{array}$ & $\begin{array}{l}\text { Average years } \\
\text { participants had spent } \\
\text { raising a child with ID }\end{array}$ & Parents/Guardians & $\begin{array}{l}\text { Educational Level of } \\
\text { Participants }\end{array}$ \\
\hline \multirow{2}{*}{22 females } & \multirow{2}{*}{15 years } & Mothers 25 & Post-high school 5 \\
\cline { 3 - 4 } & Fathers 3 & Foster parents 3 & High school 18 \\
\hline & Guardians 4 & Primary school 7 \\
\hline
\end{tabular}


Since all participants are parents of learners who have an ID, their experiences of support were taken to be similar; this allowed for a common thread to be developed during the focus group discussions (see Vaughn et al., 2006). Purposive sampling (Babbie, 2013; Brink et al., 2006) was therefore employed because we knew that the participants would be knowledgeable and could, at least potentially, provide rich information and comprehensive data about the topic we set out to explore.

\section{Data collection instruments}

Data was collected through focus group discussions, observations, and field notes during September and October 2013. We conducted four focus group discussions (one at each of the participating schools), after school hours, with each lasting between 60 and 90 minutes. Furthermore, we relied on observing the dynamics between and among the participants during the focus group discussions, and made field notes (see Babbie, 2013; Cohen et al., 2005).

Following Hoffman (2009), we thus used multiple data collection and documentation strategies to obtain in-depth insight into the phenomenon we set out to explore, and, following Cohen et al. (2005), to enhance the trustworthiness of our study. Even though we prepared and were guided by a focus group schedule we remained flexible and allowed the discussions to flow and develop based on the contributions of the participants. Participants were asked, mainly, to share their experiences of any support services that had been rendered to them, what these entailed, and the benefits they implied.

\section{Data analysis}

We conducted inductive thematic data analysis (Cohen et al., 2011; Holloway \& Wheeler, 2002; Polit \& Beck, 2006) for the purposes of our study. Krueger (1994) reiterated that qualitative analysis, particularly focus group analysis, should occur concurrently with data collection so we commenced with data analysis once the first data collection session had been completed. As already mentioned, we employed inductive thematic data analysis during data collection and afterwards. In conducting our analysis, we attempted to identify broad recurring ideas when we reviewed the data for the first time, and we coded relationships and patterns. In line with the suggestions made by Bradley et al. (2007), after reading and rereading the transcripts and field notes, we categorised related ideas in terms of three themes and related sub-themes; namely: the process of diagnosis and referral; the support received by parents; and their on-going need for additional support.

\section{Ethics}

After obtaining permission to conduct our study from the Department of Basic Education and the relevant school principals, we obtained ethical clearance from the ethics committee of the University of Pretoria ${ }^{1}$ to conduct research. We then obtained informed consent from the participating parents. All ethical protocols were observed, and participants were informed of

$1 \quad$ Reference number EP/13/04/01 
our respect for and adherence to the ethical guidelines of confidentiality, privacy, anonymity, risk, and protection from harm as advocated by Leedy and Ormrod (2005).

\section{Findings}

Following the thematic analysis we completed, we identified three themes concerning the experiences and ongoing support needs of parents raising learners with an ID. Theme 1 relates to the process of diagnosis and referral of learners who have an ID; theme 2 focuses on support received by parents; and theme 3 concerns the ongoing needs of parents for additional support. For the purposes of this article, and in response to the concern of most of the participants, we focus only on the last theme. Participants' repeated emphasis on the question, "What will happen to him [or her] when I am no longer around?" is indicative of their uncertainty about the future of their children, and their related need for ongoing support in preparation for, and following, the school-leaving phase. We identified three categories that support the theme.

\section{Need for ongoing medical and related specialised support}

In terms of medical support and assistance, parents expressed the need for these services to be continual and accompanied by medical certificates that could be used to access other required services. Participants reported that the interactional relationships between and among them and the professionals did not provide sufficient support during all developmental stages of their children's lives. One of the participants pleaded, "The support relationship between the doctors and parents of children who are intellectually disabled must not just end after the diagnosis because we need more information and guidance afterwards." Some parents went so far as to perceive the lack of continued support as a form of neglect. As one said, "I think doctors abandon us too early when we need them the most, since they are the ones who revealed the disability to us."

According to the participants, the support services they received seldom included the provision of specialised services. Parents expressed their appreciation for the support they received from schools, teachers, and selected service providers. Research by McConkey et al. (2008) as well as by Sahay et al. (2013) support the participants' experiences, a few examples of which are captured in the following excerpts, taken from the data.

I think most of the support I receive comes from the schoolteachers and the school's occupational therapist. We're still lacking the services of other specialists like a social worker, speech therapist, and a physiotherapist.

The support we get from the school is still not good enough, we still do not have the services of a speech therapist, social workers, and other relevant services for our children.

Parents' desire to remain fully informed about the best way to optimally support their children seemed to underlie the need for specialised support. Based on their concerns about 
their children's well-being and day-to-day functioning, parents expressed the ongoing need to acquire additional knowledge and skills that they could apply in practice, as was also found to be the case in a study conducted by Catherall and Iphofen (2006). To this end, one of the participants provided the following representative view.

If we can beef up our schools with other relevant professionals for learners with intellectual disabilities because we have very few professionals at this school, and they cannot cover all the needs required by learners and parents. I would like to see parents improving their knowledge in supporting their children.

These findings correlate with the work of Chadwick et al. (2002) on respite care for children with a severe ID, along with McConkey's (2011) evaluation of short breaks and intensive support services to families and disabled young people whose behaviour may be determined to be severely challenging. In highlighting the participants' experience that ongoing support provision does not meet their existing need for it, the findings of the current study also support research by Hassal et al. (2005), who emphasised the fact that formal support provision remains both limited and insufficient to address the existing needs of parents and families supporting learners who have an ID.

\section{Need for support and assistance in accessing governmental grants}

Participating parents were concerned about and frustrated with the criteria for obtaining a government disability grant for their children. Parents were of the view that professionals in the medical and social work arenas (specifically those employed by the national social security agency), could, at least potentially, support them with clear guidelines. However, parents experienced these professionals as vague about the grant criteria, and not sufficiently supportive. One of the participants explained,

My only concern is about those doctors who work for the South Africa Social Security Agency, to assess and determine whether beneficiaries are still entitled to social grants. They would say, 'If X has two hands and she is able to take herself to the toilet what is the reason for receiving [a] grant?' This confuses me a lot and makes the process of applying and accessing grant horrible and inhumane.

In addition to this, participants reported the processes involved in grant applications and renewals, as being equally horrible and inhumane. The following excerpts capture some of their frustrations with the process, particularly in terms of the financial implications and logistical challenges they experienced.

My son is wheelchair bound and this situation makes it difficult to transport him to the grant reviewing counsel, showing up to prove that he is still alive and therefore can continue to access his grant. It is very expensive ... I have to pay for a special transport to take him there.

The SASSA administrators should review their policy regarding renewal and reviewing of the beneficiaries of the grant. When they want us to bring our children, 
they must consider all the challenges involved like the long queues, the transport fares. In actual sense I would like them to go to the schools if they need to see if the beneficiary is still alive instead of letting us be absent from work and children from schools just to prove to the SASSA people that they are still alive.

This aspect of support gaps reflects problems of service delivery in South Africa that are predominant in the public sector. For instance, people who use wheelchairs do not have dedicated public transport to cater to their travelling needs. SASSA services for the renewal of grants are not accessible to those who, in most cases, have to bring along the disabled people for such renewal and it is generally difficult to accommodate these people in crowded offices. People with disabilities may be the most disadvantaged since they and/or their families often must spend money that is in very short supply to access their monthly grant disbursement.

\section{Ongoing need for support with the transition from school to work}

Corroborating the research conducted by Catherall and Iphofen (2006), the participants in our study indicated a high level of uncertainty concerning their children's transition from school to the work environment. As captured in the following excerpt, they mentioned school leaving programmes and skills training as possible strategies: "We also need programmes for our children when they exit school, we cannot afford to see our children staying home after their school time has expired."

These parents and guardians want their children to progress after leaving school, yet they seemed uncertain about available options. To them, it was important that their children possess the necessary skills to allow them entry into the work environment following their school years. One of the participants foregrounded the need for their children to be empowered enough to subsequently become independent when they said, "I would be happy if our schools could empower our children with skills that they can use to get jobs when they exit their systems so that they can also be able to fend for themselves." One of the main problems with transition to the world of work and consequent empowerment of youth with an ID could be a lack of a formalised and policy-supported transition programmes in South Africa. Large economies such as those in Britain and the U.S. have implemented transition programmes over the years to accommodate the transition needs of people with disabilities. In South Africa, more emphasis is placed on achieving the objectives of the curriculum rather than on empowering these youths with skills that are relevant for meaningful participation beyond school.

\section{Discussion}

The findings of our study indicate that, even though schools and health departments remain at the forefront in offering support to the parents of learners with an ID, many schools are still under-resourced regarding medical and specialised support as Tshiredo (2013) observed. The feeling of being abandoned by doctors appears to be strong among parents who expressed the need for on-going medical support that could ensure stability and avoid their hopping 
between doctors and getting a different diagnosis each time. Schools are often not positioned to provide the necessary support services to parents, perhaps because of the lack of sufficient occupational therapists, speech therapists, social workers, and related specialists from other support professions (Moodley et al., 2017). This results in feelings of frustration, concern, and fear among parents who are generally uncertain about the future of their children following their school years, particularly in the case of their own demise (Santacroce, 2001). The suggested framework provides for information provision through which medical practitioners could continually support parents.

The need for support and assistance in accessing government grants is experienced by many parents as a significant challenge that compromises all other support systems that they need to support their children (Barr et al., 2021). Parents require properly packaged information from the agencies responsible for grants so that they know which procedures to follow to access the grants they need for their children. Although it may seem a huge challenge for parents to bring children for verification to continue to receive the grant, it is perhaps necessary for SASSA to check regularly to avoid people in some cases claiming for children who may not be alive (Reddy \& Sokomani, 2008). However, SASSA needs, equally, to devise more effective user-friendly means of verification that will be cost effective to the end-user.

In addition to insufficient specialist service provision during the school-going years, both educational and health sectors typically terminate their support services as children progress to advanced developmental stages (Luthuli, 2020). Our study points to parents' frustration with the discontinuation of support provision by schools or other professionals the moment that learners who have an ID reach the age of 18 and have to leave school. Such lack of continued support adds to the challenges that parents face in raising these children. The need for continued support becomes especially important for children near the end of their school careers since parents cannot know what the future will hold for their children as Shands and Lewis (2020) have noted. Even though our study indicates that there is ongoing support to a few parents, this contradicts the findings from the broader literature on the transition from school to work (Steyn \& Vlachos, 2011). Transition presents challenges in many areas such as transition between grades, transition between schools, and transition from school to higher education for those who are lucky enough to experience this, and then ultimately transition into the world of work (Bell et al., 2017).

These findings resonate with and confirm current concerns and critiques of inclusive education, particularly in terms of the level of inclusion and the extent to which this will prepare children with disabilities, such as learners with an ID, for their transition to the world of work (McKenzie, 2021). Many such learners remain unemployed and continue to be the responsibility of their families who may also not be employed (Szumski \& Karwowski, 2012).

Although it would seem that special schools ought to fulfil a crucial role in the education, training, and future preparation of learners with an ID, these schools are indeed faced with a complex gamut of notable challenges. This once again points to the complexity of disability, 
its broader socio-economic contexts, and the decisions that have to be made about the future of learners who have an ID (Smith \& Lowrey, 2017). The need to empower children with an ID with job seeking skills could be catered to in a transition program but teachers are often not equipped to assist such children. Further research is recommended in order to determine whether similar results as ours would be obtained in other educational settings, including those for white people who have inherited a different socio-economic legacy, and whose lives are characterised by a different structure that includes having access to better resources and, most often, better qualified teachers.

In relation to the experiences of the participants in our study, the fears parents have often stem from their real-life experiences. Based on the lack of clear guidance or training of teachers to guide parents who need support, it seems important to develop some indicators that may steer such support efforts (Majnemer et al. 2012). This can take the form, at least potentially, of a framework for coordinated support to transition from an educational to a post-school environment that schools and teachers may use as a roadmap to guide parents seeking support. Such a framework could, in this manner, serve as guideline to learners with an ID, their parents and families, as well as to any other stakeholder supporting these children and their families. Such a framework could, furthermore, serve the purpose of highlighting the fact that ongoing support to parents of learners with an ID does not imply a singular programme or individual to provide all the required services, but calls, rather, for a multidisciplinary approach that, in not being linked to a single setting, may be implemented by schools as a first line of support.

The development of a framework for coordinated support could assist education systems to develop and implement support programmes for children, parents, and families in preparation for a child with an ID about to leave school. Even though several such programmes have been employed elsewhere, this area of support is still under-developed in South Africa. If children and their parents were more knowledgeable and better equipped for the world awaiting the school leaver, their feelings of anxiety and concern would be reduced, allowing them to focus optimally on preparation for the future of the child. However, this will require support on a broader scale by sensitising the general society into creating and maintaining an ethos of support and inclusion in South Africa.

Based on the literature reviewed and the findings of the study, the following coordinated framework for parents' on-going support is proposed. 
Figure 1:

Coordinated and On-going Parents' Support

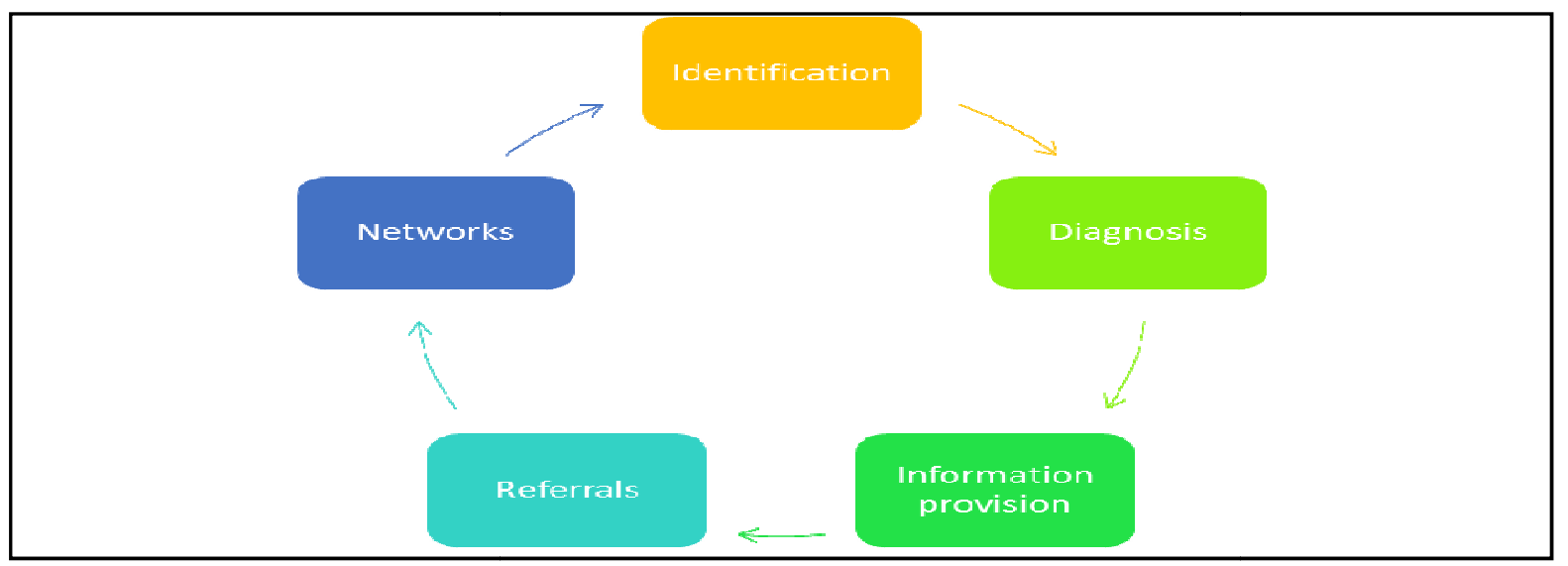

\section{Identification}

Children with an ID need to be identified early in the developmental stages to empower the parents early enough to enable them to make informed decisions about their child based on medical evidence (Reschly, 1996). Parents could be workshopped on the Screening, Identification, Assessment and Support (SIAS) process as it is used in schools.

\section{Diagnosis}

Once children have been identified, the next critical step is proper diagnosis of the type of ID and drawing up a plan regarding how the child and the parents could be supported (Ke \& Liu, 2012). Private health could partner with public health in providing diagnostic services as a social responsibility to the less privileged. SASSA-appointed doctors must provide continual information to support parents.

\section{Information provision}

Most parents may not have relevant information about the various types of IDs, let alone the one their child has. Parents require information to make informed and practical decisions about their children (Gilson et al., 2017; Machalicek et al., 2015). At this point, medical practitioners could share new knowledge with parents on how best to support these children.

\section{Referrals}

Referrals may need to be on a case-by-case basis, making use of the professionals mentioned earlier and others who may be relevant to particular cases as Tsakanikos et al., (2007) have recommended. Awareness creation should point to the partnerships that could benefit the communities through centres in universities where parents could be provided with more indepth understanding of their child's disability. 


\section{Networks}

Parents could be encouraged to form and participate in networks and support groups of people dealing with similar situations. The use of social media and the internet is encouraged to find parents around the world, some of whom may belong to well established networks that may be used as sources of information and support (Willingham-Storr, 2014).

\section{Limitations of the study}

Because of the limited number of male participants in the study, the voices of fathers and their experiences of support (or the lack of it) might not be adequately represented in our findings. Since this study was based on a case study design and focused only on the experiences of parents associated with four schools in one region, the findings cannot be generalised. The transfer of findings to similar research contexts remains discretionary.

\section{Conclusion}

The existing literature indicates that support services for parents of learners with an ID requires ongoing research. To this end, we raise some questions here pertaining to the direction that such support services may take, which framework could be followed, and how support systems may be arranged to address the needs of parents.

Based on our findings we conclude that even though some parents may feel supported, they still need structured and coordinated guidance and support by professionals. Although a philosophy of interdependency and mutual support of humanity, known as ubuntu in South Africa, informs what may be termed the spirit of hospitality, it does not seem sufficient to address the future of children with an ID.

In conclusion, we propose a framework of parents' ongoing support for identification, diagnosis, information provision, referrals, and networking as depicted in figure 1 .

\section{References}

Adnams, C. M. (2010). Perspectives of intellectual disability in South Africa: Epidemiology, policy, services for children and adults. Current Opinion in Psychiatry, 23(5), 436440.

American Psychiatric Association. (2013). Diagnostic and statistical manual of mental disorders (5th ed.). https://doi:10.1176/appi.books.9780890425596

Babbie, E. (2013). The practice of social research (13th ed.). Wadsworth.

Barr, M., Duncan, J., \& Dally, K. (2021). Parent experience of the national disability insurance scheme (NDIS) for children with hearing loss in Australia. Disability \& Society, 36(10), 1663-1687. https://doi.org/10.1080/09687599.2020.18169062 
Barron, S., McConkey, R., \& Mulvany, F. (2006). Family carers of adult persons with intellectual disabilities on the island of Ireland. Journal of Policy and Practice in Intellectual Disabilities, 3(2), 87-94. https://doi:10.1111/j.1741-1130.2006.00059.x

Bell, S., Devecchi, C., Mc Guckin, C., \& Shevlin, M. (2017). Making the transition to postsecondary education: Opportunities and challenges experienced by students with ASD in the Republic of Ireland. European Journal of Special Needs Education, 32(1), 5470.

Bolbakov, R. G., Sinitsyn, A. V., \& Tsvetkov, V. Y. (2020). Methods of comparative analysis. Journal of Physics: Conference Series, 1679(5) 052047. IOP Publishing.

Bradley, E. H., Curry, L. A., \& Devers, K. J. (2007). Qualitative data analysis for health services research: Developing taxonomy, themes, and theory. Health Services Research, 42(4), 1758-1772. https://doi:10.1111/j.1475-6773.2006.00684.x

Brink, H., Van der Walt, C., \& Van Rensburg, G. (2006). Fundamentals of research methodology for health care professionals (2nd ed.). Juta.

Capri, C., Abrahams, L., McKenzie, J., Coetzee, O., Mkabile, S., Saptouw, M., Hooper, A., Smith, P., Adnams, C., \& Swartz, L. (2018). Intellectual disability rights and inclusive citizenship in South Africa: What can a scoping review tell us? African journal of disability, 7, 396. https://doi.org/10.4102/ajod.v7i0.396

Catherall, C., \& Iphofen, R. (2006). Living with disability. Learning Disability Practice, 9(5), 15-20. https://doi:10.7748/ldp.9.5.15.s19

Chadwick, O., Beecham, J., Piroth, N., Bernard, S., \& Taylor, E. (2002). Respite care for children with severe intellectual disability and their families: Who needs it? Who receives it? Child and Adolescent Mental Health, 7(2), 66-72. https://doi:10.1111/1475-3588.00013

Chelechele, T. I. (2010). A critical analysis of the implementation of the Social Assistance Grant Policies in the North West Province of South Africa (Unpublished Master's dissertation). University of Pretoria, RSA.

Chou, Y. C., Chiao, C., \& Fu, L. Y. (2011). Health status, social support, and quality of life among family carers of adults with profound intellectual and multiple disabilities (PIMD) in Taiwan. Journal of Intellectual and Developmental Disability, 36(1), 7379. https:doi:10.3109/13668250.2010.529803

Cohen, L., Manion, L., \& Morrison, K. (2005). Research methods in education (5th ed.). Routledge Falmer.

Cohen, L., Manion, L., \& Morrison, K. (2011). Research methods in education (7th ed.). Routledge. 
Correia, R. A., Seabra-Santos, M. J., Campos Pinto, P., \& Brown, I. (2017), Giving voice to persons with intellectual disability about family quality of life. Journal of Policy and Practice in Intellectual Disabilities, 14, 59-67.

Daroch, B., Nagrath, G., \& Gupta, A. (2021). “A study on factors limiting online shopping behaviour of consumers.” Rajagiri Management Journal, 15(1), 39-52. https://doi.org/10.1108/RAMJ-07-2020-0038

Doody, O. (2012). Families' views on their relatives with intellectual disability moving from a long-stay psychiatric institution to a community-based intellectual disability service: An Irish context. British Journal of Learning Disabilities, 40(1), 46-54. https://doi:10.1111/j.1468-3156.2011.00682.x

Durrheim, K., \& Wassenaar, D. (2002). Putting design into practice: Writing and evaluating research proposals. In M. Terre-Blanche \& K. Durrheim (Eds.), Research in practice. Applied methods for the social sciences (pp. 54-71). University of Cape Town Press.

Eisenhardt, K. M., \& Graebner, M. E. (2007). Theory building from cases: Opportunities and challenges. Academy of Management Journal, 50(1), 25-32.

Engelbrecht, P. (2006). The implementation of inclusive education in South Africa after ten years of democracy. European Journal of Psychology of Education, 21(3), 253-264.

Gautam, P., Bhatia, M. S., \& Rathi, A. (2014). Intellectual disability and multiple co morbid psychiatric disorders in a child: A case report. Journal of Clinical and Diagnostic Research, 8(11), WD01-WD2. https://doi.org/10.7860/JCDR/2014/9336.5110

Gilson, C. B., Bethune, L. K., Carter, E. W., \& McMillan, E. D. (2017). Informing and equipping parents of people with intellectual and developmental disabilities. Intellectual and Developmental Disabilities, 55(5), 347-360

Hanass-Hancock, J., \& McKenzie, T. C. (2017). People with disabilities and income-related social protection measures in South Africa: Where is the gap? African Journal of Disability, 6, 1-11.

Harwick, R. M., Lindstrom, L., \& Unruh, D. (2017). In their own words: Overcoming barriers during the transition to adulthood for youth with disabilities who experienced foster care. Children and Youth Services Review, 73, 338-346.

Hassal, R., Rose, J., \& McDonald, J. (2005). Parenting stress in mothers of children with an intellectual disability: The effects of parental cognitions in relation to child characteristics and family support. Journal of Intellectual Disability Research, 49(6), 405-418. https://doi:10.1111/j.1365-2788.2005.00673.x 
Hoffman, D. M. (2009). Multiple methods, communicative preferences and the incremental interview approach protocol. Forum: Qualitative Social Research, 10(1), Article 41. http://www.qualitative-research.net/index.php/fqs/manuscript/view/1220/2656

Holloway, I., \& Wheeler, S. (2002). Qualitative research in nursing (2nd ed.). Sage.

Howitt, D. (2010). Introduction to qualitative methods in psychology. Prentice Hall.

Johnson, R. F., O'Reilly, M., \& Vostanis, P. (2006). Caring for children with learning disabilities who present problem behaviours: A maternal perspective. Journal of Child Health Care, 10(3), 188-198. https://doi:10.1177/1367493506066480

Ke, X., \& Liu, J. (2012). Intellectual disability. IACAPAP e-textbook of child and adolescent mental health. International Association for Child and Adolescent Psychiatry and Allied Professions.

Khodeir, M. S., El-Sady, S. R. \& Mohammed, H. A. E. R. (2020). The prevalence of psychiatric comorbid disorders among children with specific learning disorders: A systematic review. The Egyptian Journal of Otolaryngology, 36(1), 1-10. https://doi.org/10.1186/s43163-020-00054-w

Kitzinger, J. (2005). Focus group research: Using group dynamics to explore perceptions, experiences and understandings. In I. Holloway (Ed.), Qualitative research in health care (pp. 56-69). Open University Press.

Krueger, R. A. (1994). Focus groups: A practical guide for applied research. Sage.

Krueger, R. A., \& Casey, M. A. (2015). Focus groups: A practical guide for applied research (5th ed.). Sage.

Leedy, P. D., \& Ormrod, J. E. (2005). Practical research: Planning and design (8th ed.). Merrill/Prentice Hall.

Luthuli, M. S. (2020). The impact of weak disability grant policy mechanisms on the rights of beneficiaries and employee morale. GIS Business, 15(5), 433-452.

Machalicek, W., Lang, R., \& Raulston, T. J. (2015). Training parents of children with intellectual disabilities: Trends, issues, and future directions. Current Developmental Disorders Reports, 2(2), 110-118.

Majnemer, A., Shevell, M., Law, M., Poulin, C., \& Rosenbaum, P. (2012). Indicators of distress in families of children with cerebral palsy. Disability and Rehabilitation, 34(14), 1202-1207.

Makoelle, T. M., \& Malindi, M. (2015). Resilience: A framework for inclusive pedagogy in a South African context. Electronic Journal for Inclusive Education, 3(3), 2. 3(3), 1-16. 
Maringe, F., \& Osman, R. (2016). Transforming the post-school sector in South Africa: Limits of a skills-driven agenda. South African Journal of Higher Education, 30(5), $120-140$.

Masulani-Mwale, C., Mathanga, D., Silungwe, D., Kauye, F., \& Gladstone, M. (2016). Parenting children with intellectual disabilities in Malawi: The impact that reaches beyond coping? Child: Care, Health and Development, 42(6), 871-880.

Maxwell, V., \& Barr, O. (2003). With the benefit of hindsight: A mother's reflections on raising a child with Down syndrome. Journal of Intellectual Disabilities, 7(1), 51-64. https://doi.org/10.1177/1469004703007001983

McConkey, R. (2011). Working outside the box: An evaluation of short breaks and intensive support services to families and disabled young people whose behaviour is severely challenging. [Summary report.] University of Ulster/Watford, UK. Action for Children. https://www.actionforchildren.org.uk/media/3415/working_outside_the_box.pdf

McConkey, R., Truesdale-Kennedy, M., Chang, M. Y., Jarrah, S., \& Shukri, R. (2008). The impact on mothers of bringing up a child with intellectual disabilities: A cross-cultural study. International Journal of Nursing Studies, 45(1), 65-74. doi:10.1016/j.ijnurstu.2006.08.007

McKenzie, J. (2021). Intellectual disability in inclusive education in South Africa: Curriculum challenges. Journal of Policy and Practice in Intellectual Disabilities, 18(1), 53-57.

Moffatt, S., White, M., Mackintosh, J., \& Howel, D. (2006). Using quantitative and qualitative data in health services research: What happens when mixed method findings conflict? [ISRCTN61522618]. BMC Health Services Research, 6, 28. https://doi:10.1186/1472-6963-6-28

Moodley, R., Naidoo, S., \& Van Wyk, J. (2017). The prevalence of occupational healthrelated conditions among oral health practitioners in KwaZulu-Natal, South Africa. South African Dental Journal, 72(10), 448-454.

Polit, D. F., \& Beck, C. T. (2006). Essentials of nursing research: Methods, appraisal, and utilization (6th ed.). Lippincott Williams \& Wilkins.

Reddy, T., \& Sokomani, A. (2008). Corruption and social grants in South Africa. Institute for Security Studies Monographs, 2008(154), 1-94.

Reschly, D. J. (1996). Identification and assessment of students with disabilities. The Future of Children, 6(1), 40-53. 
Rodríguez, J. M. (2011). Métodos de investigación cualitativa (Qualitative research methods). Revista de Investigación Silogismo, 08(1), 1-34. http://www.cide.edu.co/ojs/index.php/silogismo/manuscript/view/64/53

Sahay, A., Prakash J., Khaique, A., \& Kumar, P. (2013). Parents of intellectually disabled children: A study of their needs and expectations. International Journal of Humanities and Social Science Invention, 2(7), 1-8. http://www.ijhssi.org/papers/v2(7)/Version3/A02730108.pdf

Santacroce, S. J. (2001). Measuring parental uncertainty during the diagnosis phase of serious illness in a child. Journal of Pediatric Nursing, 16(1), 3-12.

Shands, M. E., \& Lewis, F. M. (2020). Parents with advanced cancer: Worries about their children's unspoken concerns. American Journal of Hospice and Palliative Medicine ${ }^{\circledR}, 38(8), 920-926$.

Singh, T. K., Indla, V., \& Indla, R. R. (2008). Impact of disability of mentally retarded persons on their parents. Indian Journal of Psychological Medicine, 30(2), 98-104. https://doi.org/10.4103/0253-7176.48482

Smith, S. J., \& Lowrey, K. A. (2017). Applying the universal design for learning framework for individuals with intellectual disability: The future must be now. Intellectual and Developmental Disabilities, 55(1), 48-51.

Steyn, G. M., \& Vlachos, C. J. (2011). Developing a Vocational Training and Transition Planning Programme for intellectually disabled students in South Africa: A case study. Journal of Social Sciences, 27(1), 25-37.

Szumski, G., \& Karwowski, M. (2012). School achievement of children with intellectual disability: The role of socioeconomic status, placement, and parents' engagement. Research in Developmental Disabilities, 33(5), 1615-1625.

Thanh, N. C., \& Thanh, T. T. (2015). The interconnection between interpretivist paradigm and qualitative methods in education. American Journal of Educational Science, 1(2), $24-27$.

Todd, S., \& Jones, S. (2005). Looking at the future and seeing the past: the challenge of the middle year of parenting a child with intellectual disabilities. Journal of Intellectual Disability Research, 49(6), 389-404. https://doi:10.1111/j.1365-2788.2005.00675.x

Tsakanikos, E., Sturmey, P., Costello, H., Holt, G., \& Bouras, N. (2007). Referral trends in mental health services for adults with intellectual disability and autism spectrum disorders. Autism, 11(1), 9-17. 
Tshiredo, L. L. (2013). The impact of the curriculum change in the teaching and learning of science: A case study in under-resourced schools in Vhembe district (Unpublished doctoral dissertation). University of South Africa, RSA.

Van Staden, A. F. (2011). A strategy for the employment of persons with disabilities (Unpublished doctoral dissertation). University of Pretoria, RSA.

Vaughn, S., Bos, C. S., \& Schumm, J. S. (2006). Teaching students who are exceptional, diverse, and at risk in the general education classroom (4th ed.). Allan \& Bacon.

Willingham-Storr, G. L. (2014). Parental experiences of caring for a child with intellectual disabilities: A UK perspective. Journal of Intellectual Disabilities, 18(2), 146-158.

Yin, R. K. (2012). Applications of case study research (3rd ed.). Sage. 